\title{
An HER2 DNA vaccine with evolution-selected amino acid substitutions reveals a fundamental principle for cancer vaccine formulation in HER2 transgenic mice
}

\author{
Richard F. Jones ${ }^{1} \cdot$ Joyce D. Reyes ${ }^{1} \cdot$ Heather M. Gibson ${ }^{1} \cdot$ Jennifer B. Jacob ${ }^{1} \cdot$ Ulka Vaishampayan $^{1} \cdot$ Stuart Ratner $^{1}$. \\ Kang Chen ${ }^{1} \cdot$ Wei-Zen Wei ${ }^{1}$
}

Received: 10 September 2018 / Accepted: 26 March 2019 / Published online: 8 June 2019

(c) Springer-Verlag GmbH Germany, part of Springer Nature 2019

\begin{abstract}
Enhancement of endogenous immunity to tumor-associated self-antigens and neoantigens is the goal of preventive vaccination. Toward this goal, we compared the efficacy of the following HER2 DNA vaccine constructs: vaccines encoding wild-type HER2, hybrid HER2 vaccines consisting of human HER2 and rat Neu, HER2 vaccines with single residue substitutions and a novel human HER2 DNA vaccine, ph(es)E2TM. ph(es)E2TM was designed to contain five evolution-selected substitutions: M198V, Q398R, F425L, H473R and A622T that occur frequently in 12 primate HER2 sequences. These $\mathrm{ph}(\mathrm{es}) \mathrm{E} 2 \mathrm{TM}$ substitutions score 0 to 1 in blocks substitutions matrix (BLOSUM), indicating minimal biochemical alterations. $\mathrm{h}(\mathrm{es}) \mathrm{E} 2 \mathrm{TM}$ recombinant protein is recognized by a panel of anti-HER2 $\mathrm{mAbs}$, demonstrating the preservation of HER2 protein structure. Compared to native human HER2, electrovaccination of HER2 transgenic mice with ph(es)E2TM induced a threefold increase in HER2-binding antibody $(\mathrm{Ab})$ and elevated levels of IFN $\gamma$-producing T cells. ph(es)E2TM, but not pE2TM immune serum, recognized HER2 peptide p95 ${ }_{355}$ LPESFDGDPASNTAP $_{369}$, suggesting a broadening of epitope recognition induced by the minimally modified HER2 vaccine. ph(es)E2TM vaccination reduced tumor growth more effectively than wild-type HER2 or HER2 vaccines with more extensive modifications. The elevation of tumor immunity by $\mathrm{ph}(\mathrm{es}) \mathrm{E} 2 \mathrm{TM}$ vaccination would create a favorable tumor microenvironment for neoantigen priming, further enhancing the protective immunity. The fundamental principle of exploiting evolution-selected amino acid substitutions is novel, effective and applicable to vaccine development in general.
\end{abstract}

Keywords HER $2 \cdot$ Cancer vaccine $\cdot$ Human $\cdot$ Primate $\cdot$ Evolution selected

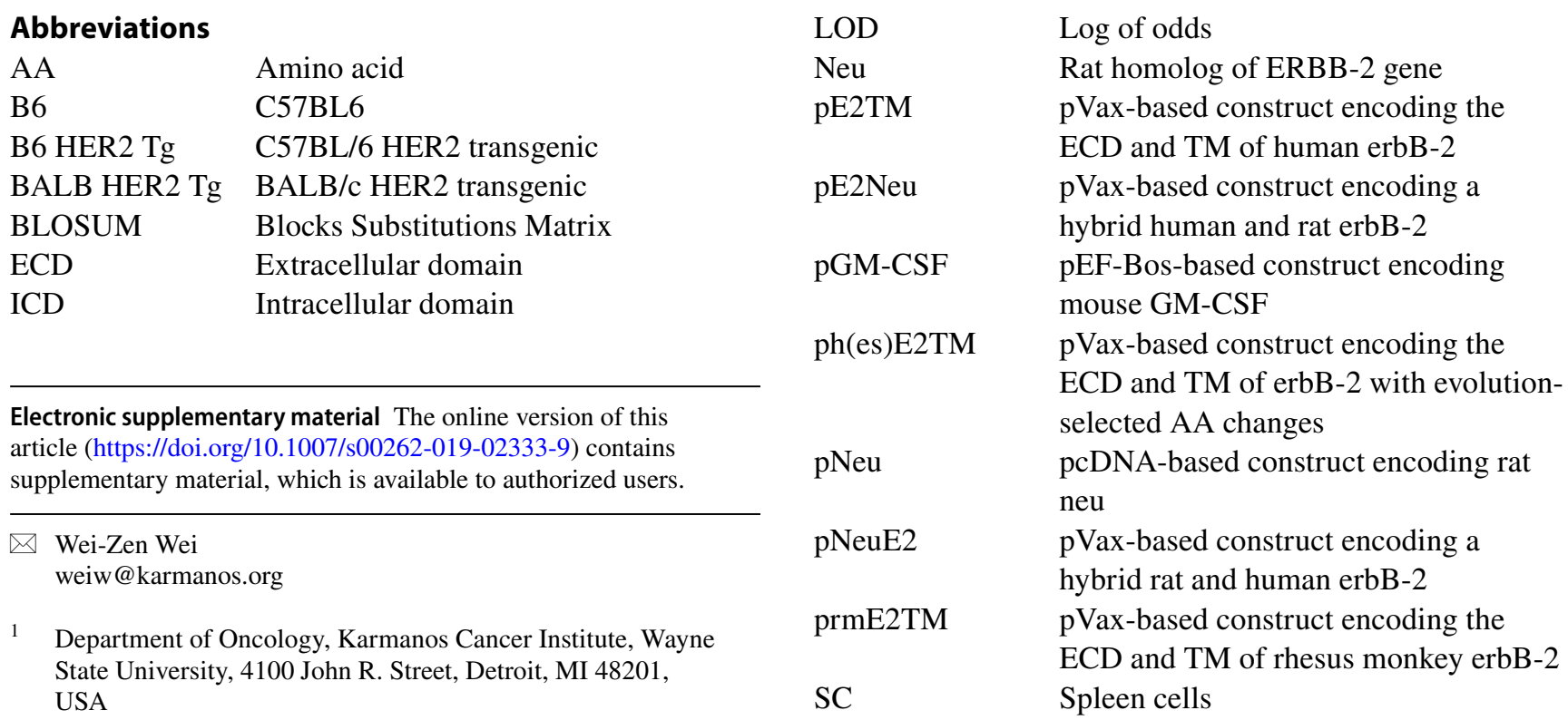




$\begin{array}{ll}\text { STR } & \text { Short tandem repeat } \\ \text { Tg } & \text { Transgenic } \\ \text { TM } & \text { Transmembrane domain } \\ \text { USDA } & \text { United States Department of } \\ & \text { Agriculture } \\ \text { WAP } & \text { Whey acidic protein } \\ \text { wt } & \text { Wild type }\end{array}$

\section{Introduction}

Clinical successes of checkpoint inhibitors have demonstrated that endogenous immunity can destroy tumors. Although some tumor infiltrating lymphocytes (TIL) recognize neoantigens, the majority of TIL clones recognized tumor-associated self-antigens (TAA) [1]. Additionally, active vaccination targeting known TAA may create a favorable tumor microenvironment for neoantigen priming to enhance immune protection. Only limited success, however, has been achieved from cancer vaccines targeting unmodified TAA [2]. While this could be due to immune suppressive mechanisms such as immune checkpoints and regulatory $\mathrm{T}$ cells, the greatest challenge remains in the balance between self-tolerance and tumor immunity. Here, we tested a new strategy to overcome immune tolerance by exploiting common amino acid (AA) substitutions occurring during evolution.

HER2 is an epidermal growth factor receptor [3] that is over-expressed in a variety of cancers to stimulate tumor growth, and endogenous HER2 immunity is found in patients $[4,5]$. Both humoral and cellular HER2 immunity contribute to tumor growth inhibition, whether by direct killing through antibodies or $\mathrm{T}$ cells, or by Ab-dependent cell-mediated cytotoxicity, culminating in a comprehensive, multi-effector anti-tumor response.

Our HER2 DNA vaccines have evolved through three generations of construction and testing. The original HER2 vaccines were designed to be free of oncogenic kinase activity. Two of the first generation constructs have advanced to clinical trials [6-8]. pE2A, encoding a kinase dead full-length HER2, induced T cell response in breast cancer patients [7], and a kinase-free, truncated $\mathrm{pE} 2 \mathrm{TM}$ is in an ongoing trial (NCT01730118). The second generation vaccines incorporated heterologous rat Neu to boost immunity. Heterologous antigen, a different species' antigen with limited sequence alterations, has been used to manifest or amplify experimental autoimmunity or tumor immunity [9-17]. In the hybrid vaccine pE2Neu, human HER2 extracellular (ECD) subdomains III and IV were replaced by the corresponding residues from rat neu. A reverse construct, pNeuE2, has human HER2 subdomains I and II replaced by rat neu residues. Until now, $p E 2 \mathrm{Neu}$ has been our most effective experimental HER2 vaccine $[1,13]$. In contrast, pNeuE2 is a surprisingly poor vaccine, showing the importance of preserving ECD subdomains I and II in HER2 vaccines.

To quantify the biochemical alteration from AA substitutions in cancer vaccines, the blocks substitutions matrix (BLOSUM) score was utilized [18, 19]. BLOSUM scores are log of odds (LOD) calculated from the frequency of AA substitutions in closely related protein sequences. The observed LOD score of the 20 natural amino acids is +4 to +11 . Higher values indicate the invariance of those residues. BLOSUM62, the basis of the protein BLAST program, was established by comparing protein blocks containing $>62 \%$ sequence identity [20]. For all possible AA substitutions, each has an observed BLOSUM log score of +3 to -4 , with $95 \%$ of the substitutions scoring between +1 and -4 . A zero indicates a substitution with a "neutral probability", i.e., equal probability of the alternative or original AA residue occurring. Positive BLOSUM scores indicate conservative substitutions with little impact on the protein. Very negative scores such as -4 indicate extremely rare substitution, which have a 10,000-fold greater chance than the score of 0 for protein alterations. We show that an HER2 protein with 5 AA substitutions scoring between 0 and +1 is sufficiently immunogenic to overcome self-tolerance, yet maintains the native structure for $\mathrm{Ab}$ recognition. BLOSUM scoring is a simple and objective quantifier to guide vaccine design and may be extrapolated to other TAAs or to the study of autoimmune or infectious diseases.

\section{Materials and methods}

\section{Construction and validation of DNA constructs}

pVAX1 (Thermo Fisher Scientific, Ann Arbor, MI) was used for constructing the following vaccines. pE2TM contains codons 1-687 of human variant 1 ErbB2 cDNA (NM004448) with the transgene inserted between Hind $I I I$ and $\mathrm{XbaI}$ within the multiple cloning site [12]. pNeu contains codons 1-692 of the rat Neu oncogene cDNA (X03362). pE2Neu contains codons 1-390 of NM-004448, a GAA TTCGCT bridge, then codons 395-692 of X03362 [12, 13, 21]. prmE2TM contains codons 1-687 of rhesus (Macaca mulatta) variant X1 ErbB2 (XM_001090430)(GenScript) and was inserted between the Nhe $I$ and $\mathrm{Xba} I$ sites in pVAX1. ph(es)E2TM is pE2TM with five codon substitutions (M198V, Q398R, F425L, H473R and A622T) and was inserted utilizing the Nhe I and XbaI sites. Candidate DNA constructs were validated by transient transfection into NIH 3T3 cells using Lipofectamine (Invitrogen, Thermo Fisher Scientific), following the manufacturer's instructions. mAbs TA-1 (Ab5; Calbiochem, San Diego, CA), N12, N29 [22, 23] (both hybridomas provided by Dr. Yosef Yarden, Weissman Inst) and trastuzumab [24] (Genentech, South San 
Francisco, CA) were used to characterize HER2 epitopes. mAb 7.16.4 (Ab4, Calbiochem, San Diego, CA) was used to detect the rat neu epitope [25]. PE-goat-anti-mouse IgG or PE-mouse-anti-human IgG (Jackson ImmunoResearch Laboratories, Inc., West Grove, PA) were secondary Abs. Samples were analyzed on a BD FACScanto II using FlowJo v10.5 software (TreeStar, Ashland, OR, USA).

\section{Cell culture}

All tissue culture reagents were purchased from Invitrogen, Theromo Fisher and cultured as previously described [13]. Transfected cell lines were maintained in medium containing G418, puromycin or zeocin.

\section{Derivation of D2F2/E2t}

D2F2/E2 cells $\left(2 \times 10^{5}\right.$ cells $)$ were inoculated into the mammary fat pads of female BALB/c mice and the outgrowth was serially transplanted into naïve female BALB/c mammary fat pads for a total of seven generations. Tumor cells were dissociated after the seventh transplantation and cloned. The cell clones with the highest HER2 expression were selected and designated D2F2/E2t. D2F2/E2t was maintained in medium containing $0.6 \mathrm{mg} / \mathrm{ml} \mathrm{G} 418$.

\section{DNA electrovaccination}

Test DNA constructs have been described above. pcDNA/ $\mathrm{Neu}$ (pNeu) encoding the extracellular and transmembrane domains of rat neu has been previously described [26]. pEF-Bos/granulocyte macrophage colony-stimulating factor (pGM-CSF) encoding murine GM-CSF was provided by Dr. N. Nishisaka at Osaka University, Osaka, Japan, as previously described [27]. Mice were electrovaccinated as described [27]. Briefly, mice were anesthetized and $50 \mu \mathrm{g}$ test DNA in an admix with $20 \mu \mathrm{g}$ pGM-CSF in $50 \mu \mathrm{lBS}$ was injected i.m. in the quadriceps. Immediately following injection, square wave electroporation using a BTX830 (BTX Harvard Apparatus) or NEPA21 super electroporator (Nepa Gene) was applied [13] with pulses at $100 \mathrm{~V}$ with $20 \mathrm{~ms}$ duration delivered eight times in two opposite orientations. Mice were electrovaccinated one to three times at 2 weeks intervals as described in "Results".

\section{Regulatory T cell depletion}

In B6 HER-2 $\mathrm{Tg}$ mice, regulatory $\mathrm{T}$ cells (Treg) were depleted 10 days prior to vaccination by injection i.p. of $0.5 \mathrm{mg}$ anti-CD25 mAb PC61.

\section{Immune monitoring}

Sera, peripheral blood lymphocytes (PBL) and(or) splenocytes (SC) were collected 2 weeks following the last electrovaccination. Anti-HER $2 \mathrm{Ab}$ in sera were measured by binding to HER2 overexpressing SKOV3 cells using flow cytometry, and $\mathrm{Ab}$ concentrations calculated by regression analysis using mAb TA-1 as the standard [28]. Normal mouse serum or isotype matched $\mathrm{mAb}$ was the control. Antineu Ab were measured with 3T3/NKB cells and the standard curve generated using mAb 7.16.4 (Ab4). Differences in $\mathrm{Ab}$ concentration were analyzed by the Student's $t$ test.

ELISpot reagents were purchased from BD Biosciences. HER2 reactive T cells were enumerated by IFN- $\gamma$ ELISpot $[13,29]$. PBL or SC was incubated for $48 \mathrm{~h}$ with the APC 3T3/EKB or TC-1/E2 (3T3/KB and TC-1 were negative controls) at an APC:lymphocyte ratio of 1:10 or with recombinant HER2 or neu protein (ecd-Fc fusion; SinoBiological). Results were expressed as number of cytokine-producing cells per $10^{6} \mathrm{SC}$. Data were analyzed using Student's $t$ test.

\section{BLOSUM scores}

Blocks substitutions matrix (BLOSUM) scores [20] are LOD calculated from the frequency of AA substitutions in closely related protein sequences. BLOSUM62 was established by comparing protein blocks containing $>62 \%$ sequence identity (http://www.ncbi.nlm.nih.gov/Class/FieldGuide/BLOSU M62.txt).

\section{Peptide-binding profiling}

Peptide-binding analysis was performed with a microarray that displays a library of 168 HER2 ECD 15-mer peptides with 11-mer overlap (JPT Peptide Technologies, Germany). The peptides were covalently immobilized on glass slides (PepStar Peptide Microarrays, JPT). Immune serum samples diluted 1:200 were incubated on the array for $1 \mathrm{~h}$ at $30{ }^{\circ} \mathrm{C}$. Bound $\mathrm{Ab}$ was visualized with a fluorescently labeled anti-mouse IgG. After washing and drying, the slides were scanned at $635 \mathrm{~nm}$ to obtain fluorescence intensity profiles. The images were quantified to generate a mean pixel value for each peptide. A color-coded heat map was computed to show relative fluorescence intensities.

\section{Inhibition of tumor cell proliferation}

Inhibition of tumor cell proliferation was measured by incubating the human breast cancer cell line SK-BR-3 with HER2 immune serum in a flat bottom 96-well plate. Serum from mice receiving blank pVax was the negative control. 
(a)

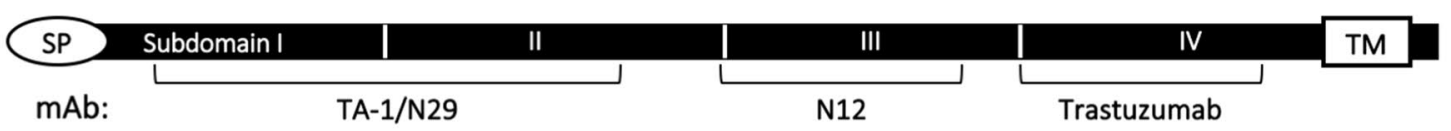

(b)
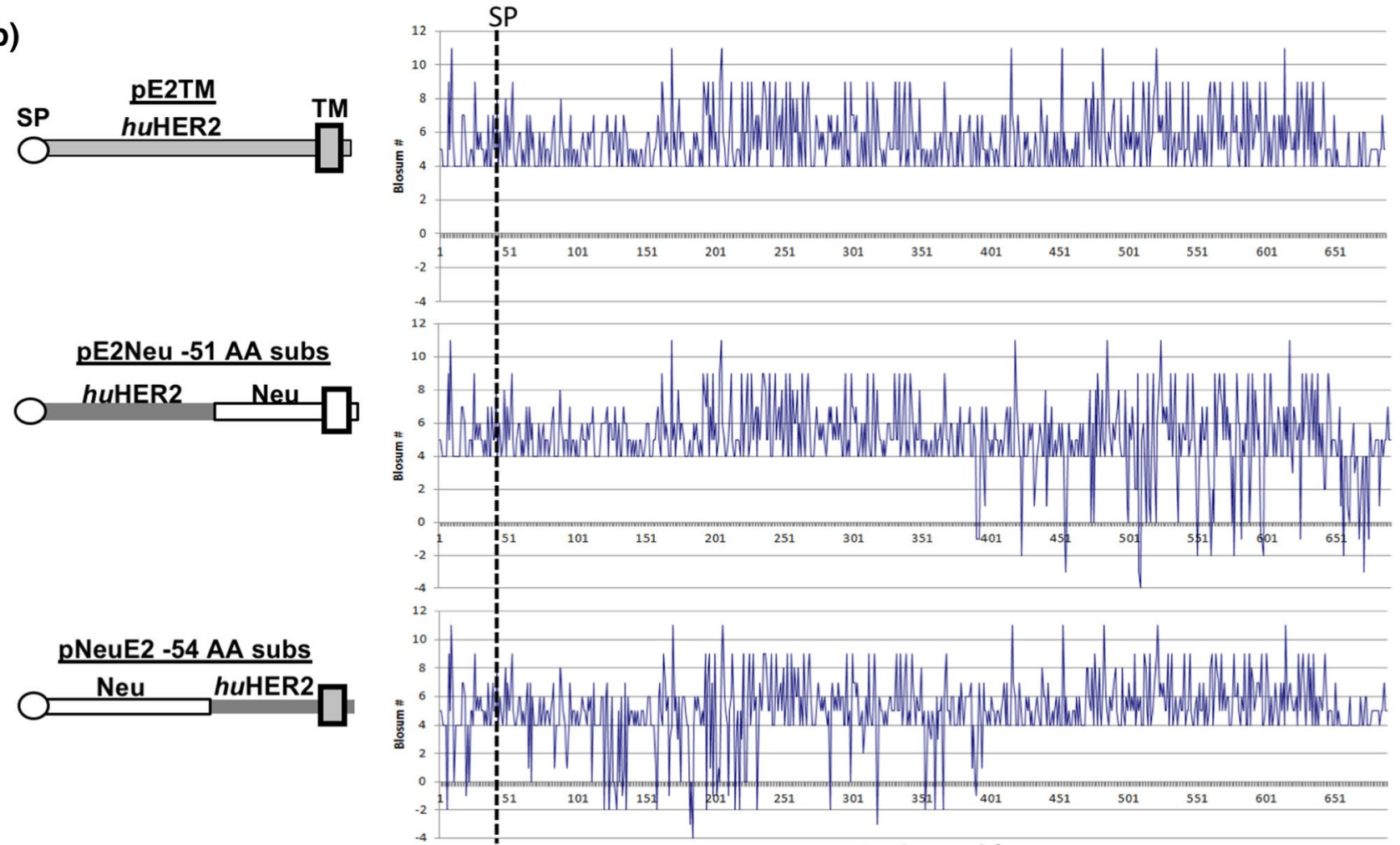

Amino acids

(c)
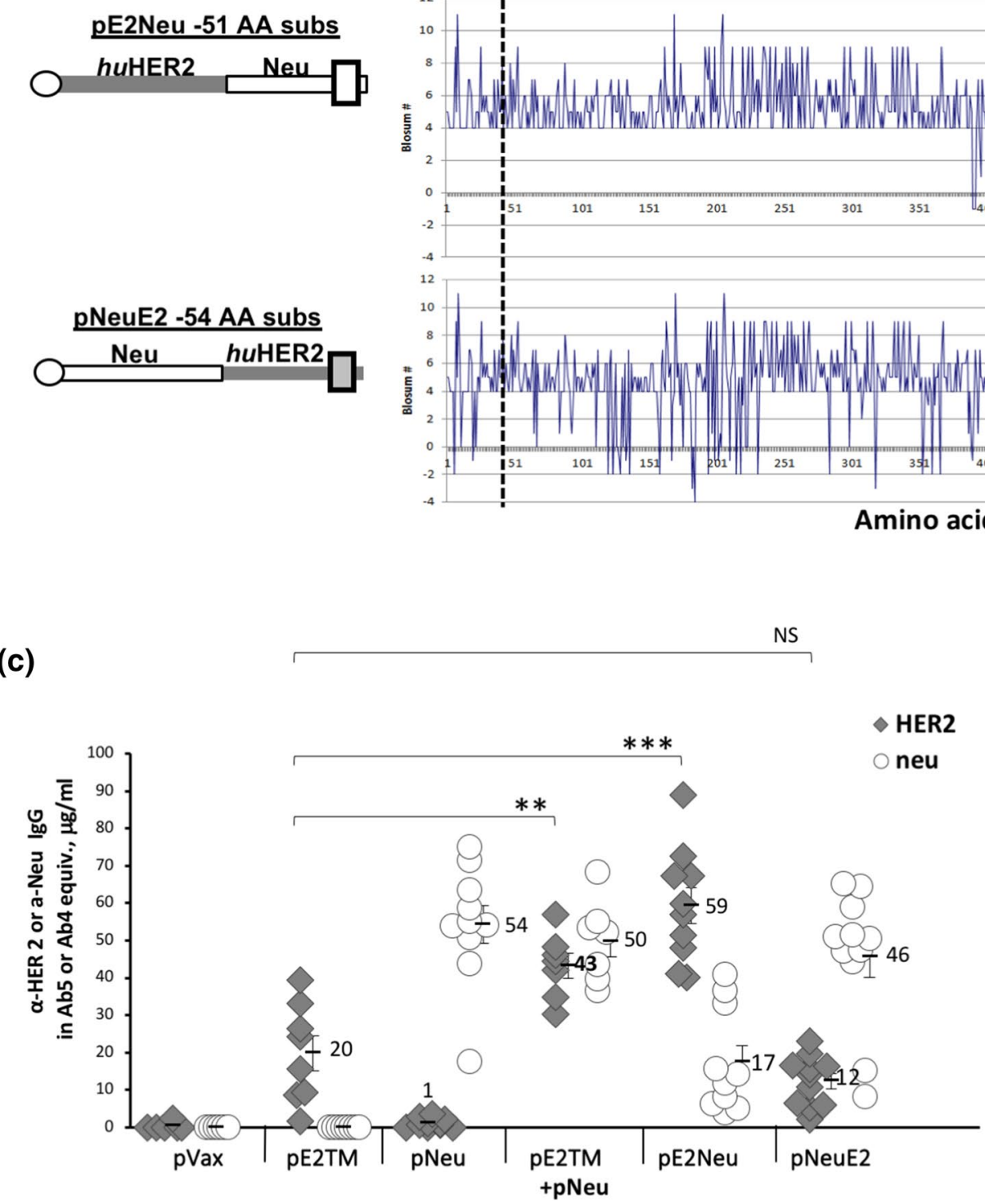
४Fig. 1 HER2 vaccines and BLOSUM scores. a HER2 ECD subdomains I-IV and the mAbs reactive to each subdomain are shown. Signal peptide (SP) and transmembrane domain (TM) are also indicated. b BLOSUM62 scores were plotted for each vaccine. For AA substitutions, BLOSUM scores are calculated relative to human HER2 (top row). pE2TM is wt HER2 (AA residues 1-687). pE2Neu contains wt HER2 SP and subdomains I and II (residues 1-390), fused to rat Neu (residues 394-691) with three extra residues AEF inserted between HER2 and neu due to cloning strategy. pNeuE2 is the converse of pE2Neu, containing Neu SP and subdomains I and II, fused to HER2 (residues 391-687). c BALB HER2 Tg Mice received 3X DNA electrovaccination with $\mathrm{pE} 2 \mathrm{TM}, \mathrm{pNeu}$, the hybrid vaccines $\mathrm{pE} 2 \mathrm{Neu}$, pNeuE2 or admixed pE2TM and pNeu. The levels of anti-neu or antiHER-2 $\mathrm{Ab}$ in the immune sera were measured by flow cytometry. There were six to nine mice per group. ${ }^{*} p<0.01$, *** $p<0.0001$

Gefitinib was used as positive control. Cell survival was measured by Alamar Blue assay after $48 \mathrm{~h}$ of incubation. Statistical significance was determined by Student's $t$ test.

\section{Inhibition of tumor growth in vivo}

BALB HER2 Tg mice were electrovaccinated twice with pE2Neu or ph(es)E2TM at 2 week intervals. Two weeks after the second vaccination, D2F2/E2t cells were implanted into \#4 mammary fat pad and tumor growth was monitored by palpation twice/week. Tumor size was measured and calculated by $X Y^{2} / 2$ where $X$ represents the longer axis and $Y$ the short axis.

\section{Results}

\section{Hybrid HER2 vaccine constructs}

The AA BLOSUM scores were evaluated in three existing HER2 vaccines (Fig. 1a/b). pE2TM encodes native HER2 ECD and TM domains and a 12 AA fragment of the ICD. Two hybrid constructs $\mathrm{pE} 2 \mathrm{Neu}$ and $\mathrm{pNeuE} 2$, each contains distinct AA substitutions. Figure $1 \mathrm{~b}$ shows BLOSUM scores for the 687 residues in pE2TM (top row), ranging from +4 to +11 . Relative to $\mathrm{pE} 2 \mathrm{TM}$, $\mathrm{pE} 2 \mathrm{Neu}$ contains 51 substitutions in ECD subdomains III/IV and 3 extra residues (AEF) in ECD subdomain III, following codon \#389, due to DNA cloning methodology. Thirty-two of the 51 substitutions were conservative, with BLOSUM scores $\geq 0$. The other 19 scored -1 to -4 . The reverse construct, pNeuE2, harbors 54 neu-derived AA substitutions in subdomains I/II with 25 non-conservative changes scoring at -1 to -4 .

The potency of these vaccines was compared in BALB HER2 Tg mice [20]. Mice were electrovaccinated $3 \times$, at 2 weeks intervals, as described in "Materials and methods" and $\mathrm{Ab}$ levels measured 2 weeks following each vaccination. Vaccination control was pVax. Also tested were $\mathrm{pNeu}$ encoding rat neu, and admixed pE2TM and pNeu. Figure 1c shows HER2-binding Ab (shaded diamonds) induced by DNA electrovaccination. Compared to pE2TM, pE2Neu and admixed $\mathrm{pE} 2 \mathrm{TM}+\mathrm{pNeu}$ induced two- to threefold elevation of $\operatorname{IgG}(59 \pm 15$ or $43 \pm 9$ vs $20 \pm 13 \mu \mathrm{g} / \mathrm{ml})$, implicating heterologous neu epitopes in promoting HER 2 self-reactivity. The large number of substitutions, however, makes it difficult to project how the vaccine will perform in humans who present the antigenic peptides in the context of human, rather than mouse, major histocompatibility complexes. The reverse hybrid, pNeuE2, did not enhance HER2 Ab even though anti-neu $\mathrm{Ab}$ was high $(46 \pm 18 \mu \mathrm{g} / \mathrm{ml})$ [13].

\section{HER2 vaccines with single amino acid substitutions}

Increased $\mathrm{Ab}$ response in HER2 $\mathrm{Tg}$ mice projected $\mathrm{pE} 2 \mathrm{Neu}$ as an effective vaccine. However, the structural, biochemical and immunological impacts of over $50 \mathrm{AA}$ alterations are too complex to extrapolate to other TAA. Toward a rational vaccine design, we tested $\mathrm{pE} 2 \mathrm{TM}$ vaccines harboring single AA substitutions because of our previous findings from a feline vaccination trial [30]. A single conservative Q141K substitution (BLOSUM score $=+1$ ) in the feline HER2 vaccine elevated $\mathrm{T}$ cell response in one of three cats without altering $\mathrm{Ab}$ response. Hence, a panel of six $\mathrm{pE} 2 \mathrm{TM}$ vaccines with selected single AA substitutions was generated.

Glutamine $(\mathrm{Q})$ or asparagine $(\mathrm{N})$ located on the external surface of HER2 was replaced with AA carrying BLOSUM scores $\geq 1$ : Q141K, Q213K, Q239K, Q329K, Q429R and N438D (Fig. 2a). Stable expression of all mutants except Q213K was detected in transiently transfected 3T3 cells by anti-HER 2 mAbs TA-1 and N12, indicating preservation of the protein structure (Fig. 2b). Anti-neu mAb Ab4 was a negative control. To test immunogenicity in vivo, wt $\mathrm{BALB} / \mathrm{c}$ mice were electrovaccinated $1 \times$ with the test constructs and HER2-binding Ab were measured 2 weeks following the vaccination. All but Q213K test vaccines induced Ab (Fig. 2c).

Preliminary testing of the five stable constructs shows that Q141K and Q429R mutants produced more consistent IgG response in BALB HER2 Tg mice (not shown). The immunogenicity of these two mutant HER2 vaccines was tested in comparison with $\mathrm{pE} 2 \mathrm{TM}$ and $\mathrm{pE} 2 \mathrm{Neu}$ vaccines. BALB HER2 Tg mice electrovaccinated $2 \times$ produced $48 \pm 12$, $59 \pm 8,20 \pm 11$ and $26 \pm 10 \mu \mathrm{g} / \mathrm{ml}$ HER2-binding Ab after vaccination with $\mathrm{pE} 2 \mathrm{TM}, \mathrm{pE} 2 \mathrm{Neu}, \mathrm{pE} 2 \mathrm{TM}-\mathrm{Q} 141 \mathrm{~K}$ and pE2TM-Q429R, respectively, showing no advantage of single residue substitutions (Fig. 2d). Two time vaccination of Treg-depleted C57BL/6 (B6) HER2 Tg mice with $\mathrm{pE} 2 \mathrm{TM}$, pE2Neu or pE2TM-Q141K induced $7 \pm 5,48 \pm 12$ and $9 \pm 6 \mu \mathrm{g} / \mathrm{ml}$ HER2-binding Ab (Fig. 2e). Treg were depleted 10 days before vaccination because this mouse strain responds poorly in the presence of Treg [31]. Q141K mutants induced elevated HER2-specific IFN- $\gamma$-producing $\mathrm{T}$ 

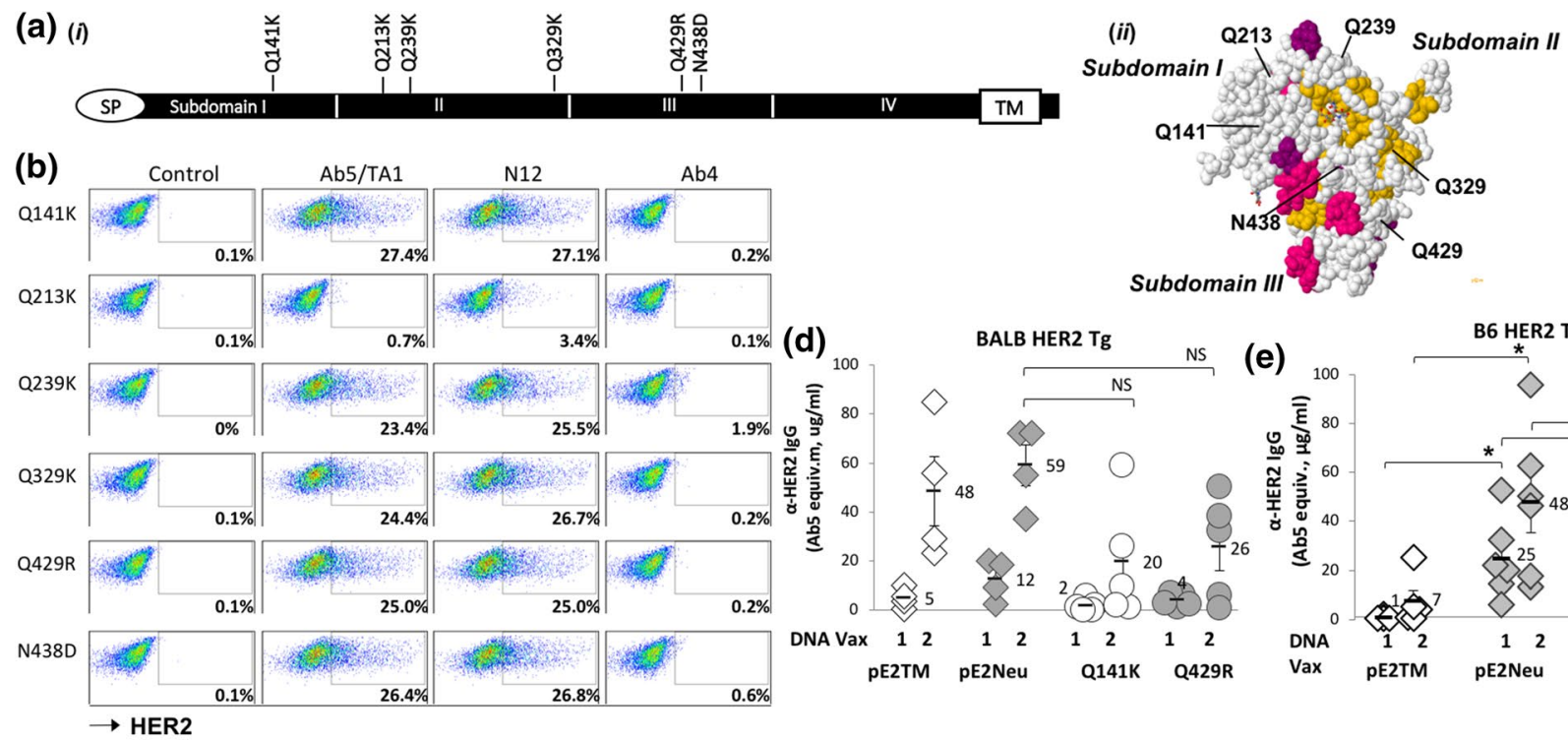

(c)

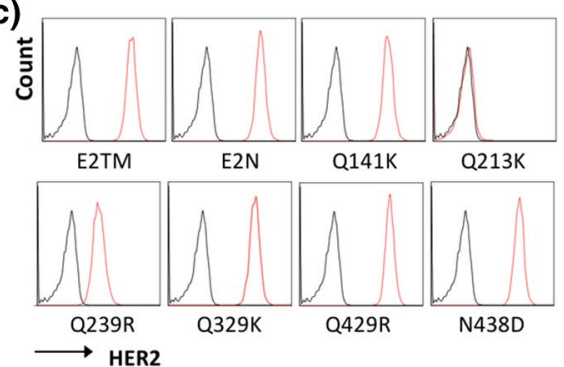

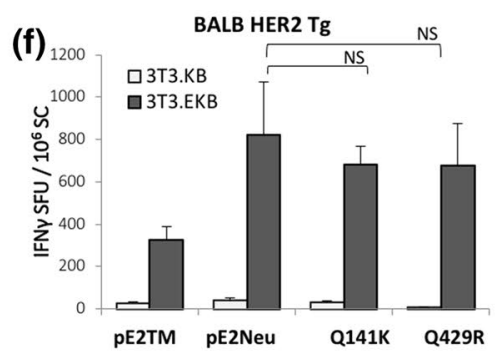
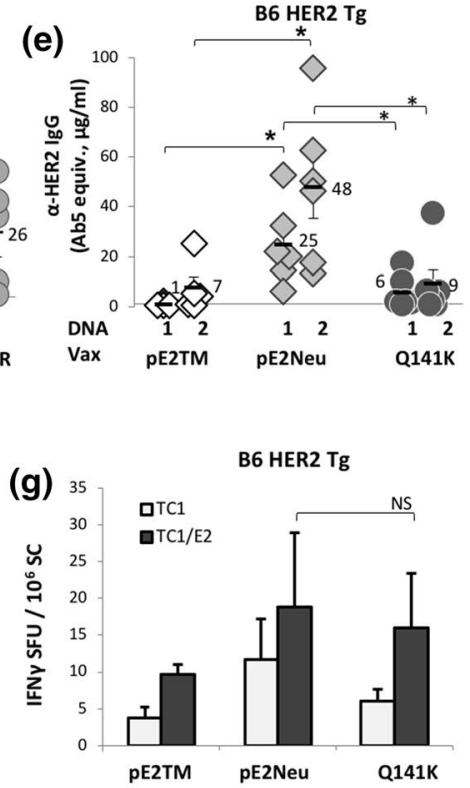

Fig. 2 Human HER2 point mutants: stability and immunogenicity. ai Single residue substitutions are depicted on the DNA scheme and in the space-filling model (RCSB 2A91, JSmol viewer) (aii). b Point mutations were expressed as recombinant proteins in NIH 3T3 cells, then analyzed by flow cytometry using anti-HER $2 \mathrm{mAb}$ Ab5 and N12 as detection Ab. Anti-neu mAb Ab4 was the negative control. c BALB/c wt mice were electrovaccinated $1 \times$ with test constructs encoding the point mutants and $\mathrm{Ab}$ response was monitored 2 weeks post-vaccination (red line histogram). d-g Immunogenicity of selected point mutants was tested in BALB HER-2 or B6 HER-2

cells in BALB HER2 Tg mice when compared with pE2TM (Fig. 2f), but not in B6 HER2 Tg (Fig. 2g). Therefore, the overall trend that single residue substituted constructs are less effective than $\mathrm{pE} 2 \mathrm{Neu}$ is shown in both BALB HER2 $\mathrm{Tg}$ and B6 HER2 Tg mice.

\section{Evolution-selected HER2 vaccine ph(es)E2TM}

Because both a large number of AA substitutions in hybrid vaccines and minimal change in single residue substitutions are not optimal for cancer vaccination, we tested the hypothesis that primate HER2 proteins with few AA disparities resemble human HER2 to preserve the antigenic epitopes, but carry sufficient alterations to elevate self-reactivity. Common AA substitutions were sought in HER2 sequences from 12 primate species that share $>95 \%$ sequence identity
Tg mice. Mice were electrovaccinated $2 \times$ with $\mathrm{pE} 2 \mathrm{TM}, \mathrm{pE} 2 \mathrm{Neu}$, pE2TM-Q141K, or pE2TM-Q429R. d/f In BALB HER-2 Tg mice, HER-2 Ab levels were measured by flow cytometry following each vaccination and IFN $\gamma$-producing $\mathrm{SC}$ were measured by ELISPOT assay after $2 \times$ vaccination using $3 \mathrm{~T} 3 / \mathrm{EKB}$ cells as the APC (3T3/KB as controls). e/g In B6 HER-2 Tg mice, Treg were depleted 10 days prior to vaccination. Mice were vaccinated $2 \times$. HER $2 \mathrm{Ab}$ levels were measured by flow cytometry, while IFN $\gamma$-producing SC were measured by ELISPOT assay with the APC TC-1/E2 (TC-1 as control). There were four to six mice per group. ${ }^{*} p<0.05$

with human HER2 (Supplemental Table 1a/b). Of these 'evolution-selected alterations', 5 AA in HER2 ECD are frequently replaced by a common residue (Supplemental Table 1a): M198V (ECD subdomain I), Q398R (III), F425L (III), H473R (III) and A622T (IV) (Fig. 3a). BLOSUM scores of these substitutions are all 0 and +1 , indicating relatively neutral changes. A new HER2 vaccine was generated to incorporate these five substitutions: ph(es)E2TM (Fig. 3b). Alterations in ph(es)E2TM are readily quantifiable (Supplemental Fig. 1). A rhesus monkey HER2 (rmE2TM) (XM_001090430) encoded two additional AA substitutions that are more drastic and not commonly observed: P122L in subdomain I (BLOSUM score $=-3$ ) and P625S in subdomain IV (score $=-2$ ) (shaded blocks in Fig. 3a) [32]. To determine whether drastic AA substitutions would detract immune response from native HER2, the prmE2TM DNA 
(a)

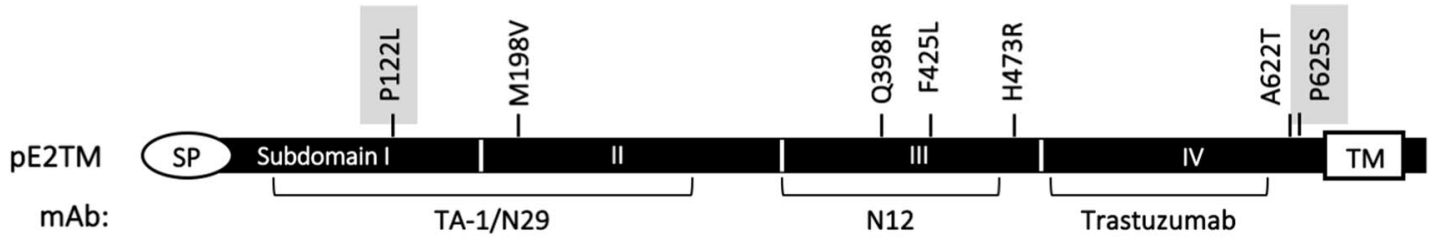

(b)

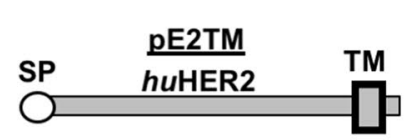

ph(es)E2TM (5 AA subs)

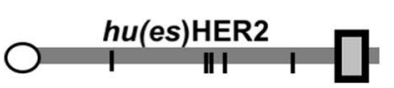

prmE2TM (7 AA subs)

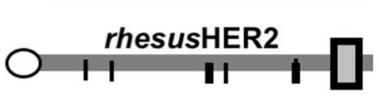

(c)

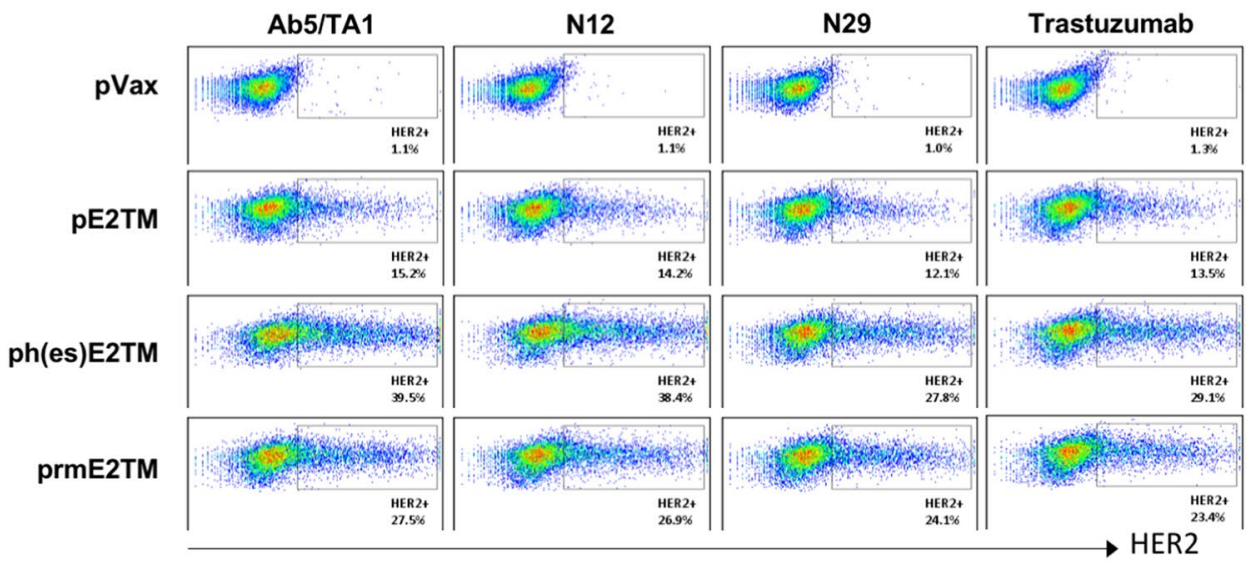

(d)

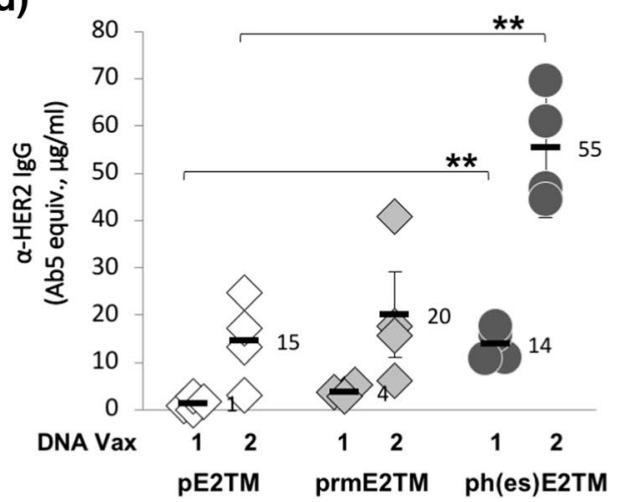

Fig. 3 The novel evolution-selected HER2 vaccine and the corresponding immune response. $\mathbf{a} / \mathbf{b}$ Positions of AA substitutions are depicted. Shaded substitutions are unique to rhesus monkey (XP_001090430). c Expression of recombinant proteins. 3T3 cells were transfected with ph(es)E2TM or prmE2TM and analyzed by flow cytometry. pE2TM and pVax blank vector were also tested;

construct with all seven residue substitutions was generated for comparison.

\section{Expression and immunogenicity of ph(es)E2TM and prmE2TM}

Expression of recombinant protein was measured by flow cytometry using $3 \mathrm{~T} 3$ cells transiently transfected with ph(es) (e)

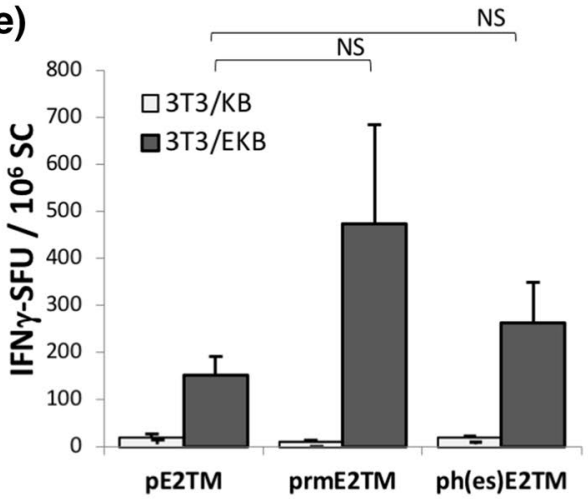

positive cells are identified in a box. d/e Induction of HER2 specific response by the test vaccine constructs. BALB HER2 Tg mice were electrovaccinated $2 \times$ with pE2TM, prmE2TM, or ph(es)E2TM. HER2 specific d Ab and e IFN $\gamma$-producing SC were measured after the last vaccination. There were four mice per group. ${ }^{*} p<0.01$

E2TM or prmE2TM (Fig. 3c). Controls were pVax and pE2TM. Anti-HER2 mAb TA1, N12, N29 and trastuzumab recognized both ph(es)E2TM and rmE2TM recombinant proteins, indicating preservation of these epitopes.

Immunogenicity of ph(es)E2TM and prmE2TM versus native $\mathrm{pE} 2 \mathrm{TM}$ was compared. BALB HER2 Tg mice were electrovaccinated $2 \times$ and anti-HER 2 response monitored (Fig. 3d, e). HER2-binding Ab increased by more than 
threefold in ph(es)E2TM immunized mice $(55 \pm 6$ vs $15 \pm 5$, $p<0.01$ ), showing augmented HER 2 immunogenicity from the five substitutions. In contrast, prmE2TM did not enhance HER2 Ab response ( $20 \pm 7$ vs $15 \pm 6 \mu \mathrm{g} / \mathrm{ml}$ ) (Fig. 3d). It is possible that $\mathrm{P} 122 \mathrm{~L}$ and $\mathrm{P} 625 \mathrm{~S}$ substitutions resulted in neoantigen to detract immunity from native HER2 (Fig. 3d). HER2-specific IFN- $\gamma$-producing $T$ cells were induced in pE2TM, prmE2TM and ph(es)E2TM vaccinated mice at $152 \pm 39,474 \pm 211$ and $264 \pm 85$ spot-forming units $/ 10^{6} \mathrm{SC}$, respectively (Fig. 3e). There may be a trend toward higher $\mathrm{T}$ cell response in prmE2TM and ph(Es)E2TM immunized mice, but the difference was not statistically significant.

Immunogenicity of ph(es)E2TM was also compared with pE2Neu in BALB and B6 HER2 Tg mice. Mice were electrovaccinated $2 \times, 2$ weeks apart, and serum was collected 2 weeks after each vaccination. B6 HER2 Tg mice received mAb PC61 before vaccination to remove Treg. Figure 4a shows pE2TM, pE2Neu and ph(es)E2TM inducing $12 \pm 1.8$, $38 \pm 4.3$ and $37 \pm 4.3 \mu \mathrm{g} / \mathrm{ml}$ HER2-binding Ab, respectively,
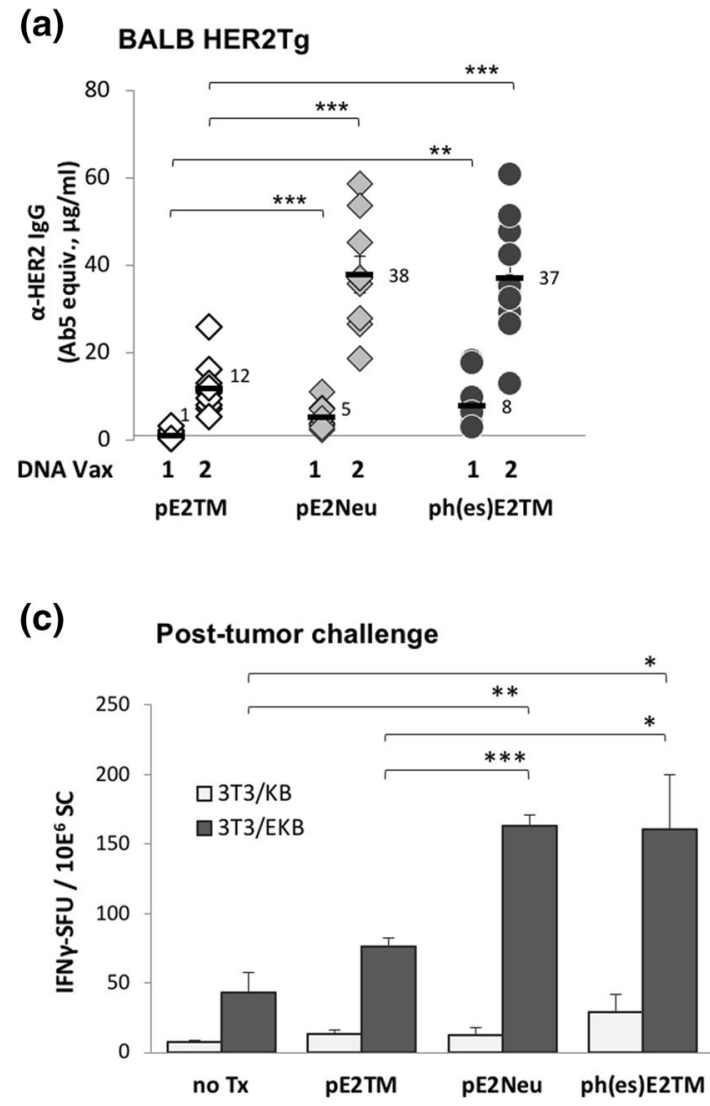

Fig. 4 Induction of HER2 immunity by ph(es)E2TM. BALB HER2Tg (a) and Treg-depleted B6 HER2 Tg (b) mice were electrovaccinated $2 \times$ with pE2TM, pE2Neu, or ph(es)E2TM. HER2 Ab levels were measured 2 weeks after each vaccination. c BALB HER2 Tg mice were inoculated with D2F2/E2t tumors in the mammary fatpad in BALB HER2 Tg mice. ph(es)E2TM and pE2Neu induced comparable levels of HER2-binding IgG even though ph(es) E2TM has only 5 substituted residues. In Treg-depleted, $2 \times$ vaccinated B6 HER2 Tg mice, pE2Neu and ph(es)E2TM induced $48 \pm 12.4 \mu \mathrm{g} / \mathrm{ml}$ and $57 \pm 12.4 \mu \mathrm{g} / \mathrm{ml}$ HER2-binding $\mathrm{Ab}$, respectively, compared to $7 \pm 4.6 \mu \mathrm{g} / \mathrm{ml}$ by $\mathrm{pE} 2 \mathrm{TM}$ (Fig. 4b). Therefore, in both BALB and B6 HER2 Tg mice, $\mathrm{ph}(\mathrm{es}) \mathrm{E} 2 \mathrm{TM}$ was as effective as pE2Neu in generating $\mathrm{Ab}$ to self HER2. Of the 5 substituted AA, four are located in ECD subdomains III and IV. M198V substitution in subdomain I has a BLOSUM score of +1 . Incorporation of conservative AA substitutions selected and preserved during evolution resulted in an improved HER2 vaccine for Ab induction.

To measure HER2-specific $T$ cell response, $2 \times$-vaccinated BALB HER2 $\mathrm{Tg}$ mice received intra-fat pad injection of syngeneic D2F2/E2t mammary tumor cells expressing human HER 2 at 2 weeks post 2 nd vaccination. Immune SC harvested 3 weeks later showed a significant increase in $\mathrm{T}$ cell response in $\mathrm{ph}(\mathrm{es}) \mathrm{E} 2 \mathrm{TM}$ or $\mathrm{pE} 2 \mathrm{Neu}$ vaccinated

(b)
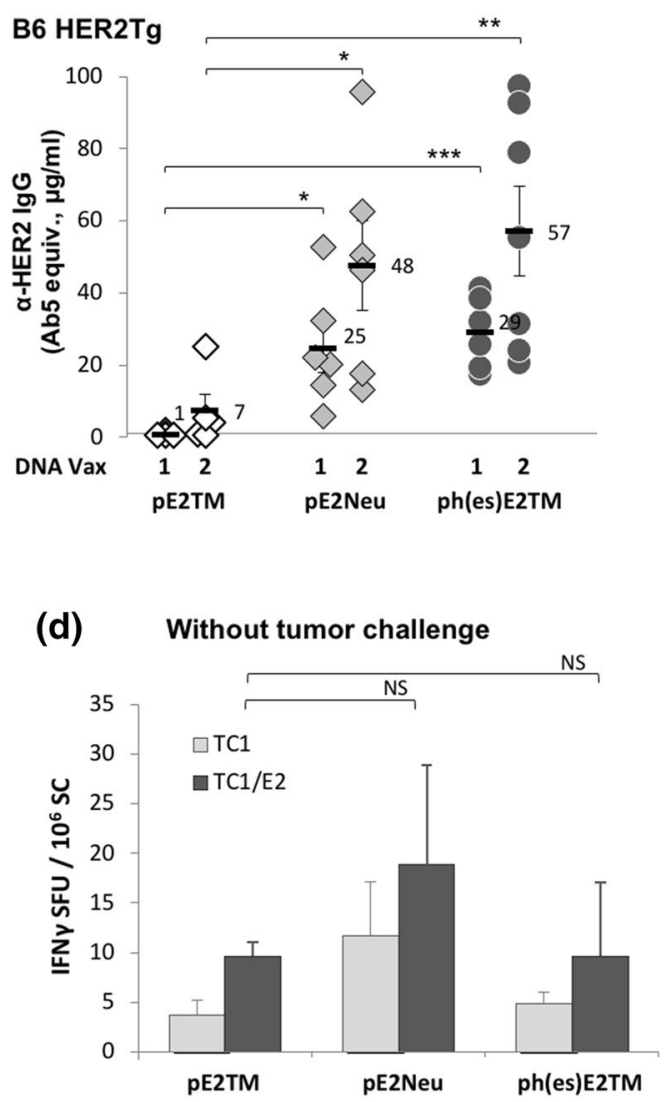

and IFN $\gamma$-producing SC were analyzed 4 weeks post-tumor inoculation, d IFN $\gamma$-producing SC in B6 HER2 Tg were evaluated 2 weeks post-second vaccination, without tumor inoculation. There were six to nine mice per group. ${ }^{*} p<0.05,{ }^{* *} p<0.01,{ }^{* * *} p<0.0001$ 
mice, when compared to pE2TM immunization (Fig. 4c). A modest $\mathrm{T}$ cell response was induced in B6 HER2 Tg mice regardless of the vaccine. Note that B6 HER2 Tg mice were not challenged with tumors (Fig. 4d). Taken together, ph(es) E2TM, like pE2Neu, induced elevated humoral immunity in both strains of mice and elevated T cell immunity in BALB HER2 Tg mice.

\section{Peptide-binding profiles of immune serum}

To determine the epitopes recognized by the immune serum, a library of 168 human HER2 15-mer peptides with 11-mer overlaps was used to evaluate the Ab-binding profile. Immune serum was incubated on the peptide microarray slide and bound antibodies were detected with a fluorescence-labeled anti-mouse $\mathrm{IgG}$ and scanned at $635 \mathrm{~nm}$. Specific binding was expressed by the fold increase in mean pixel value for a particular peptide over the average pixel values of all peptides excluding three non-specific binding peptides $(85,121$ and 128) (Fig. 5a and Supplemental Fig. 2). An arbitrary cutoff of twofold increase was used to identify positive binding peptides.

A single P95 ${ }_{355} \mathrm{LPESFDGDPASNTAP}_{369}$ emerged as the target of the immune serum from B6 HER2 Tg mice that received pE2Neu (2/5) or ph(es)E2TM (2/5), but not pE2TM (0/5). In BALB HER2 Tg mice, pE2Neu immune serum recognized p95 (5/5), but not ph(es)E2TM or pE2TM immune serum. p95 in subdomain III is situated on the external surface of HER2 ECD (Fig. 5b). Interestingly, in pE2Neu, the 3 $\mathrm{AA}$ insertion (AEF) introduced during $\mathrm{pE} 2 \mathrm{Neu}$ construction is located between residue 368 and 369 within p95 and may contribute to the exposure of p95 in E2Neu. Further study will be required to determine if $\mathrm{p} 95$-binding $\mathrm{Ab}$ contributes positively or negatively to anti-tumor immunity.

(a)

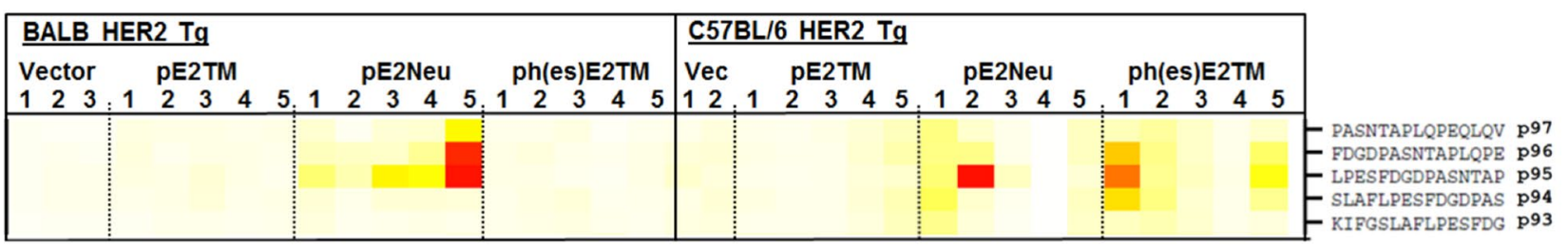

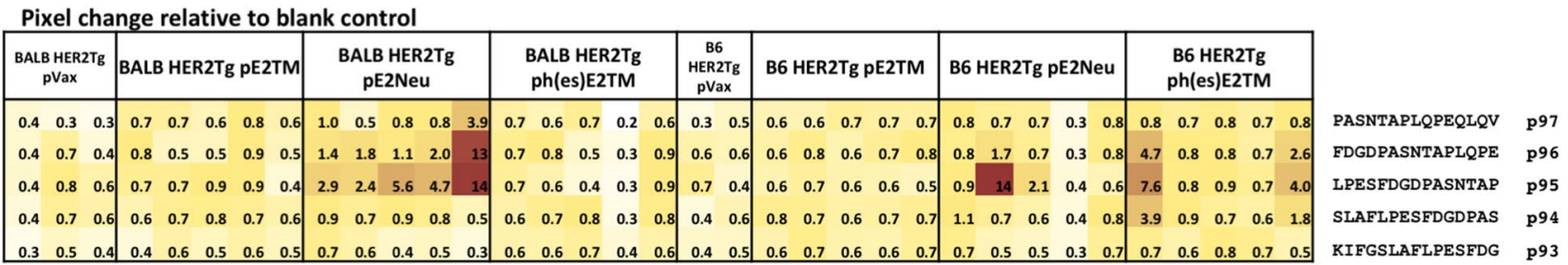

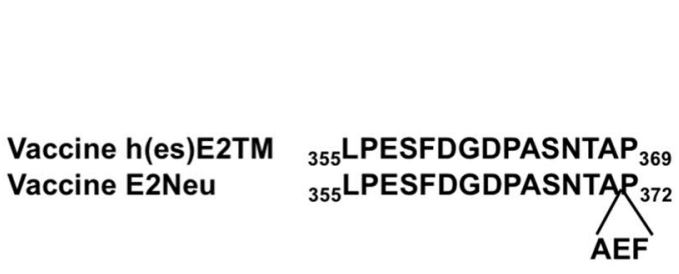

Fig. 5 HER2 immune serum epitope mapping. Immune serum was incubated on peptide microarray slide containing a library of 168 human HER2 15-mer peptides with 11-mer overlaps. Bound antibodies were detected with a fluorescence-labeled anti-mouse IgG. Specific binding was expressed by the fold increase in mean pixel value for a particular peptide over the average pixel values of all peptides. A twofold increase is considered positive binding. a The binding profile of immune sera from BALB HER2 and B6 HER2 Tg mice vac- (b)

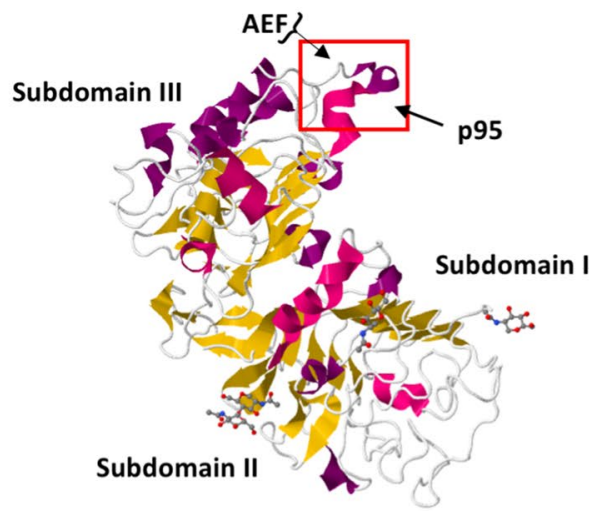

cinated with pVax, pE2TM, pE2Neu or ph(es)E2TM. p95 ${ }_{355}$ LPESFDGDPASNTAP $_{369}$ was recognized most prominently by pE2Neu and ph(es)E2TM immune sera. b The position of cognate peptide domain p95 is indicated in the ribbon model of human HER2 (RCSB 2A91, JSmol viewer). Three extra residues AEF introduced during pE2Neu construction is located between residues 368 and 369 within p95 


\section{Vaccine induced anti-tumor immunity}

Functionality of HER2 immune serum was measured by incubating graded concentrations of immune serum from BALB HER2 Tg mice (Fig. 4) with human SK-BR-3 cells for $48 \mathrm{~h}$ (Fig. 6). Surviving cells were quantified by Alamar Blue. Reduction in cell survival at 45, 20 and $40 \%$ was observed when the cells were incubated with $3 \mu \mathrm{g} /$ $\mathrm{ml}$ of pE2TM, pE2Neu and ph(es)E2TM immune serum, respectively. At $1 \mu \mathrm{g} / \mathrm{ml}$, only pE2TM (15\% inhibition) and $\mathrm{ph}(\mathrm{es}) \mathrm{E} 2 \mathrm{TM}$ (25\% inhibition) immune sera inhibited tumor cell proliferation. Examination of $\operatorname{IgG}$ subtypes indicates similar $\mathrm{IgG} 1 / \mathrm{IgG} 2$ composition in the three test sera (data not shown).

The efficacy of controlling tumor growth in vivo was compared in BALB HER2 Tg mice (Fig. 6b). After $2 \times$ electrovaccination, mice received $2 \times 10^{5} \mathrm{BALB} / \mathrm{c}$ D2F2/ E2t cells in their \#4 fat pads. Tumor growth was monitored twice weekly. Tumor volume was reduced in mice whether they were vaccinated with $\mathrm{pE} 2 \mathrm{Neu}$ or $\mathrm{ph}(\mathrm{es})$ E2TM, but reduction was greater and statistically significant in ph(es)E2TM immunized mice.

\section{Discussion and conclusions}

An effective HER2 cancer vaccine, ph(es)E2TM, was produced by substituting just five AA that occur frequently in closely related primates. These five substitutions (M198V, Q398R, F425L, H473R and A622T) are relatively conservative as defined by their BLOSUM scores of 0 to +1 . The structure of critical proteins such as HER2 may be highly conserved during evolution to preserve their function, resulting in minimal AA deviations. This selection process resulted in a natural design template for generating TAA vaccines to boost endogenous immunity. Vaccination with ph(es)E2TM induced HER2 immunity that inhibited tumor growth in HER2 $\mathrm{Tg}$ mice. Introduction of two additional drastic substitutions, P122L (score $=-3$ ) and P625S (score $=-2$ ), abolished elevated response to HER2, showing that inclusion of uncommon substitutions can be detrimental.

The test vaccines were delivered by intramuscular DNA electroporation. Naked plasmid DNA can be readily generated and modified. It is stable and relatively easy to produce
Fig. 6 Inhibition of tumor growth in vitro and in vivo. a Inhibition of SK-BR-3 tumor cell proliferation in vitro. Cells were incubated with increasing concentrations of HER2binding $\mathrm{Ab}$ from the vaccinated BALB HER2 Tg mice shown in Fig. 4. The negative control was pVax immune serum and the positive control was Gefitinib. Cell viability was measured by Alamar Blue assay. Values are mean \pm SE from three independent samples, each in triplicate, and normalized to untreated cells. Statistical significance was determined by Student's $t$ test. b BALB HER2 Tg mice were vaccinated $2 \times$ either with pE2TM, pE2Neu or ph(es)E2TM, at 2 week intervals. D2F2/E2t cells were injected intra-fat pad and tumor growth was monitored twice weekly. $* p<0.05, * * p<0.01$, $* * * p<0.0001$

(a)

\section{SKBR3 cell proliferation Immune Sera}
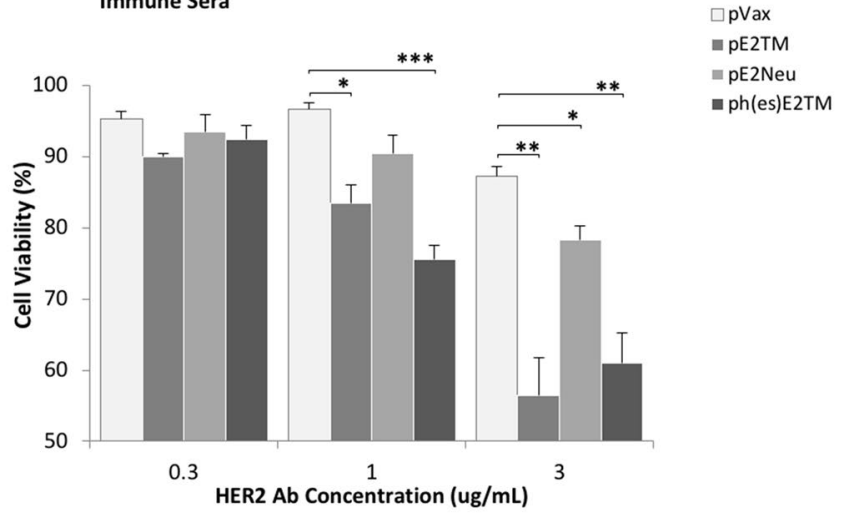

(b)

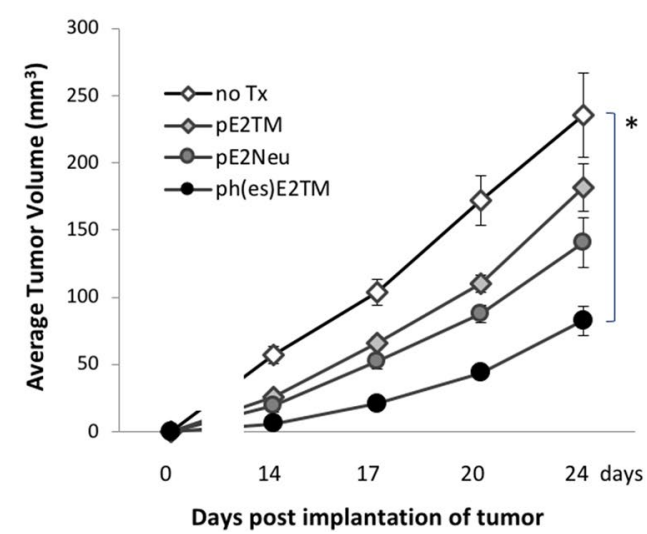

Gefitinib

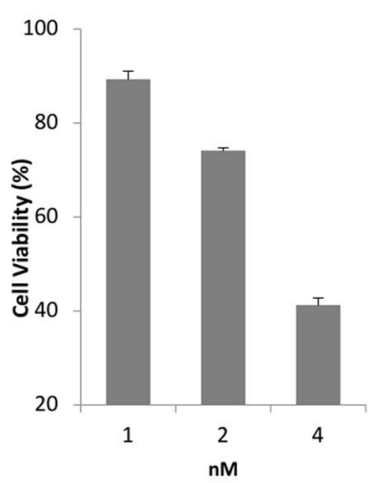


in large quantity. Intramuscular injection is safe and consistent. Application of electroporation at the injection site enhances DNA uptake and expression with little adverse effect.

Heterologous antigens have been the industry standard for overcoming self-tolerance, but without a defined formulation principle. Heterologous human collagen is routinely used to induce experimental autoimmune arthritis in HLA-DR1 Tg mice [15, 33]. Human DR1 presents collagen epitopes to $\mathrm{T}$ cells and induces highly cross-reactive antibodies to both human and mouse collagen, initiating synovitis in mice. This collagen induced arthritis model is a classic example of using a heterologous antigen to overcome self-tolerance. Human and mouse type II collagen have 4\% (51/1306) protein sequence disparity, with 17 substitutions carrying BLOSUM scores $>0$. It is not known how AA substitutions impact induction of arthritis.

The principle of immunizing with heterologous antigen was extended to the USDA-approved canine melanoma DNA vaccine [11,34-36]. The vaccine was based on human tyrosinase which contains $11.5 \%$ (59/511) sequence disparity from canine tyrosinase. Seventeen of the 59 substitutions have negative BLOSUM scores. The response of heterogeneous, outbred dogs to human tyrosinase vaccine was quite variable. Based on our findings with ph(es)E2TM, incorporation of evolution-selected, conservative substitutions may be most appropriate for boosting endogenous immunity to unmodified TAA.

The importance of preserving wt HER2 ECD subdomains I and II in vaccine construct was indicated by the poor vaccine response from pNeuE2, in which subdomains I and II were replaced with rat sequences. Critical epitopes may be lost or foreign epitopes created that detract from self HER2. Note that the predicted $\mathrm{N}$-glycosylation sites in pNeuE2 ECD subdomain I differ significantly from wt pE2TM, $\mathrm{ph}(\mathrm{es}) \mathrm{E} 2 \mathrm{TM}$ or $\mathrm{pE} 2 \mathrm{Neu}$. The post-translational glycosylation patterns may also contribute to altered antigenicity [37, 38].

The ph(es)E2TM recombinant protein is recognized by a panel of four anti-HER2 mAbs that recognize specific epitopes in subdomains I/II, III and IV, showing structural preservation of HER2 ECD. Recombinant rmE2TM was also recognized by these $\mathrm{mAbs}$, but prmE2TM was ineffective at elevating HER2-binding Ab. P122L and P625S substitutions may have resulted in new epitopes that detracted HER2 immunity.

BLOSUM scores had been used to evaluate disease progression or treatment response that involves genetically diverse pathogens. Immunity to a broad spectrum of HIV accumulates following repeated infection, protecting the exposed individuals from developing AIDS [39]. BLOSUM scores that define HIV subtypes, clades and epitope drift are predictive of anti-HIV T cell affinity
[40]. BLOSUM scores have also been used to predict detrimental versus tolerated amino acid substitutions in CTL epitopes of flavivirus [41] or HBV [42]. To the best of our knowledge, the present study is the first to use BLOSUM scores to aid vaccine design for a TAA. We do recognize, however, that BLOSUM scoring is not a direct measure of immune epitope conservation or immunogenicity of the recombinant protein, but our results indicate that it is functionally related to immunogenicity.

Epitope scanning revealed a linear epitope p95 ${ }_{355}$ LPESFDGDPASNTAP $_{369}$ preferentially recognized by pE2Neu immune serum from both strains and by ph(es) E2TM immune serum from B6 HER2 Tg mice. Treg depletion in B6 HER2 Tg mice prior to vaccination may result in a broader immune recognition. Overlapping peptides p94, p96 and p97 are also recognized by the reactive immune sera, revealing ESFDGDPASNT as the core peptide. The insertion of AEF between residues 368 and 369 at the C-terminus of p95 may expose p95 for B cell and $\mathrm{Ab}$ recognition. ph(es)E2TM does not contain this insertion and the closest substitution is Q398R. Presently, it is unclear how ph(es)E2TM presents p95 because epitope scanning is limited to linear peptides. Importantly, immune sera recognize multiple HER2 epitopes including cryptic epitopes while $\mathrm{mAb}$ used in the clinic, such as trastuzumab, recognize a single epitope. Thus, A broader range of antigen-antibody interaction is achieved with vaccination induced $\mathrm{Ab}$.

In summary, the new ph(es)E2TM was tested in HER2 $\mathrm{Tg}$ mice of BALB/c and C57BL/6 backgrounds. This vaccine showed elevated immune response in both strains. Although $\mathrm{BALB} / \mathrm{c}$ and $\mathrm{C} 57 \mathrm{BL} / 6$ mice have distinct MHC genotypes, and HER2 Tg mice of these two backgrounds showed very different intrinsic response to HER2 vaccines, ph(es)E2TM induced a stronger HER2 immunity compared to native pE2TM or pE2Neu in either strain. ph(es)E2TM with evolution-selected conservative residue substitutions represents a new and novel principle for vaccine formulation.

Acknowledgements The authors acknowledge support of the Animal Model and Therapeutic Evaluation Core and the Microscopy, Imaging and Cytometry Resources of the Karmanos Cancer Institute.

Author contributions RFJ conceived the concept of evolution-selected amino acid substitution, generated the test constructs, incorporated the BLOSUM scoring system to evaluate the constructs and contributed to manuscript preparation. JDR conducted in vitro and in vivo experiments and contributed to manuscript preparation. HMG conducted an experiment using single nucleotide substitution vaccines. JBJ conducted hybrid vaccine experiments and contributed to manuscript preparation. UV provided clinical guidance on cancer vaccination. SR consulted on the design and testing of the vaccines and contributed to manuscript preparation. KC contributed to data discussion and manuscript preparation. W-ZW oversaw the entire project from conceptualization, experimentation and data interpretation to manuscript preparation. 
Funding The study is supported by NIH Grants CA076340 (WeiZen Wei) and CA216648 (Wei-Zen Wei) as well as by the Helen Kay Memorial Trust (Wei-Zen Wei) and the Herrick Foundation (Wei-Zen Wei).

\section{Compliance with ethical standards}

Conflict of interest The authors declare that they have no conflict of interest.

Ethical approval and ethical standards All animal procedures were conducted in accordance with accredited institution guidelines and the US Public Health Service Policy on Humane Care and Use of Laboratory Animals. The animal protocol for this study IACUC-17-10-0356 was approved by the Wayne State University Institutional Animal Care and Use Committee (IACUC).

Animal source Wild-type (wt) $\mathrm{C} 57 \mathrm{BL} / 6$ and $\mathrm{BALB} / \mathrm{c}$ mice were purchased from Charles River Laboratory (Frederick, MD, US). Heterozygous B6 HER-2 Tg mice (B6 HER-2 Tg) which express fulllength wt HER-2 under the whey acidic protein (WAP) promoter were generated in our laboratory and maintained by mating with wt B6 mice [43]. BALB/c HER-2 Tg (BALB HER-2 Tg) mice were generated by back-crossing B6 HER-2 Tg mice to wild-type BALB/c mice [44] and are maintained by mating with BALB/c mice. B6 HER2 Tg mice have been deposited at Jackson lab repository (B6.Cg-Tg(WapERBB2)229Wzw/J). Transgene positive mice were identified by PCR as described [31].

Cell line authentication Antigen-presenting cells (APC) used in ELISPOT assay including 3T3/KB, 3T3/EKB and TC-1/E2 were generated as previously described [45]. BALB/c NIH 3 T3 fibroblasts were transfected with both $\mathrm{K}^{\mathrm{d}}$ and $\mathrm{B} 7.1(\mathrm{CD} 80)$ to generate $3 \mathrm{~T} 3 / \mathrm{KB}$, or with the addition of HER 2 for 3T3/EKB. 3T3/NKB similarly generated to express neu was used for measuring anti-neu Ab levels in the immune serum. The expression of the transgenes is validated by flow cytometry using mAb to $\mathrm{K}^{\mathrm{d}}$ (SF1-1.1, Biolegend), B7.1 (CD80, BD), HER2 (TA-1/Ab5, Calbiochem) and neu (Ab4, EMD Millipore). C57BL/6 lung epithelial cell line TC-1 expressing $\mathrm{K}^{\mathrm{b}}$ and $\mathrm{B} 7.1$ was a gift from Dr. T.C. Wu (The Johns Hopkins University, Baltimore, MD). TC-1/ E2 cells were transfected with wt HER-2 as previously described [31]. TC- 1 and TC-1/E2 cells are validated by tumor growth in B6 mice and by their expression of $\mathrm{K}^{\mathrm{b}}$ as detected by mAb Af6-88.5.5.3 (eBioscience, Thermo Fisher). D2F2 is a mouse mammary tumor line that arose originally in a BALB/c hyperplastic alveolar nodule line, D2, [46-48]. D2F2/E2 cells were generated by co-transfection with a HinDIII WAP-HER-2 expression cassette (6.9-kb) and linearized pRSV/ neo as reported [46]. D2F2/E2t cells were selected from D2F2/E2 cells by serial passage in BALB/c mice. D2F2 cells and derivatives are validated by tumor growth in BALB/c mice and by their expression of $\mathrm{Kd}$ as detected by mAb SF1-1.1. Expression of HER2 in D2F2/E2 and D2F2/E2t is verified by mAb Ab5, using flow cytometry. SK-BR-3 and SKOV3 cells were purchased from the American Type Culture Collection. Authentication of SKBR-3 and SKOV3 cells by short tandem repeat (STR) profiling was carried out with Promega's Cell ID System.

\section{References}

1. Gee MH, Han A, Lofgren SM et al (2018) Antigen identification for orphan $\mathrm{T}$ cell receptors expressed on tumor-infiltrating lymphocytes. Cell 172(549-63):e16. https://doi.org/10.1016/j. cell.2017.11.043
2. Lohmueller J, Finn OJ (2017) Current modalities in cancer immunotherapy: immunomodulatory antibodies. CARs and vaccines. Pharmacol Ther 178:31-47. https://doi.org/10.1016/j. pharmthera.2017.03.008

3. Harari D, Yarden Y (2000) Molecular mechanisms underlying ErbB2/HER2 action in breast cancer. Oncogene 19:6102-6114. https://doi.org/10.1038/sj.onc.1203973

4. Moasser MM (2007) The oncogene HER2: its signaling and transforming functions and its role in human cancer pathogenesis. Oncogene 26:6469-6487. https://doi.org/10.1038/ sj.onc. 1210477

5. Taylor C, Hershman D, Shah N et al (2007) Augmented HER-2 specific immunity during treatment with trastuzumab and chemotherapy. Clin Cancer Res 13:5133-5143. https://doi. org/10.1158/1078-0432.CCR-07-0507

6. Miller F, Jones RF, Jacob J, Kong YC, Wei WZ (2004) From breast cancer immunobiology to her-2 DNA vaccine and autoimmune sequelae. Breast Dis 20:43-51

7. Norell H, Poschke I, Charo J et al (2010) Vaccination with a plasmid DNA encoding HER-2/neu together with low doses of GM-CSF and IL-2 in patients with metastatic breast carcinoma: a pilot clinical trial. J Transl Med 8:53. https://doi. org/10.1186/1479-5876-8-53

8. Wei WZ, Shi WP, Galy A, Lichlyter D, Hernandez S, Groner B, Heilbrun L, Jones RF (1999) Protection against mammary tumor growth by vaccination with full-length, modified human ErbB-2 DNA. Int J Cancer 81:748-754

9. Christadoss P, Lindstrom JM, Talal N, Duvic CR, Kalantri A, Shenoy M (1986) Immune response gene control of lymphocyte proliferation induced by acetylcholine receptor-specific helper factor derived from lymphocytes of myasthenic mice. J Immunol 137:1845-1849

10. Christadoss P, Poussin M, Deng C (2000) Animal models of myasthenia gravis. Clin Immunol 94:75-87. https://doi.org/10.1006/ clim.1999.4807

11. Grosenbaugh DA, Leard AT, Bergman PJ et al (2011) Safety and efficacy of a xenogeneic DNA vaccine encoding for human tyrosinase as adjunctive treatment for oral malignant melanoma in dogs following surgical excision of the primary tumor. Am J Vet Res 72:1631-1638. https://doi.org/10.2460/ajvr.72.12.1631

12. Jacob J, Radkevich O, Forni G, Zielinski J, Shim D, Jones RF, Wei WZ (2006) Activity of DNA vaccines encoding self or heterologous Her-2/neu in Her-2 or neu transgenic mice. Cell Immunol 240:96-106. https://doi.org/10.1016/j.cellimm.2006.07.002

13. Jacob JB, Quaglino E, Radkevich-Brown O, Jones RF, Piechocki MP, Reyes JD, Weise A, Amici A, Wei WZ (2010) Combining human and rat sequences in her-2 DNA vaccines blunts immune tolerance and drives antitumor immunity. Cancer Res 70:119-128. https://doi.org/10.1158/0008-5472.CAN-09-2554

14. Miller SD, McRae BL, Vanderlugt CL, Nikcevich KM, Pope JG, Pope L, Karpus WJ (1995) Evolution of the T-cell repertoire during the course of experimental immune-mediated demyelinating diseases. Immunol Rev 144:225-244

15. Myers LK, Rosloniec EF, Cremer MA, Kang AH (1997) Collagen-induced arthritis, an animal model of autoimmunity. Life Sci 61:1861-1878

16. Nelson RW, Beisang D, Tubo NJ et al (2015) T cell receptor crossreactivity between similar foreign and self peptides influences naive cell population size and autoimmunity. Immunity 42:95107. https://doi.org/10.1016/j.immuni.2014.12.022

17. Swanbord RH, Stepaniak JA (1996) Experimental autoimmune encephalomyelitis in the rat. In: Coligan JE, Kruisbeek AM, Margulies DH (eds) Current protocols in immunology. Wiley, New York, pp 15.2.1-15.2.4

18. Henikoff S, Henikoff JG (1992) Amino acid substitution matrices from protein blocks. Proc Natl Acad Sci USA 89:10915-10919 
19. Pertsemlidis A, Fondon JW 3rd (2001) Having a BLAST with bioinformatics (and avoiding BLASTphemy). Genome Biol 2:REVIEWS2002

20. Styczynski MP, Jensen KL, Rigoutsos I, Stephanopoulos G (2008) BLOSUM62 miscalculations improve search performance. Nat Biotechnol 26:274-275. https://doi.org/10.1038/nbt0308-274

21. Quaglino E, Mastini C, Amici A et al (2010) A better immune reaction to Erbb-2 tumors is elicited in mice by DNA vaccines encoding rat/human chimeric proteins. Cancer Res 70:2604-2612. https://doi.org/10.1158/0008-5472.CAN-09-2548

22. Bacus SS, Stancovski I, Huberman E, Chin D, Hurwitz E, Mills GB, Ullrich A, Sela M, Yarden Y (1992) Tumor-inhibitory monoclonal antibodies to the HER-2/Neu receptor induce differentiation of human breast cancer cells. Cancer Res 52:2580-2589

23. Stancovski I, Hurwitz E, Leitner O, Ullrich A, Yarden Y, Sela M (1991) Mechanistic aspects of the opposing effects of monoclonal antibodies to the ERBB2 receptor on tumor growth. Proc Natl Acad Sci USA 88:8691-8695

24. Cho HS, Mason K, Ramyar KX, Stanley AM, Gabelli SB, Denney DW Jr, Leahy DJ (2003) Structure of the extracellular region of HER2 alone and in complex with the Herceptin Fab. Nature 421:756-760. https://doi.org/10.1038/nature01392

25. Drebin JA, Stern DF, Link VC, Weinberg RA, Greene MI (1984) Monoclonal antibodies identify a cell-surface antigen associated with an activated cellular oncogene. Nature 312:545-548

26. Rovero S, Amici A, Di Carlo E et al (2000) DNA vaccination against rat her-2/Neu p185 more effectively inhibits carcinogenesis than transplantable carcinomas in transgenic BALB/c mice. J Immunol 165:5133-5142

27. Jacob JB, Kong YC, Meroueh C, Snower DP, David CS, Ho YS, Wei WZ (2007) Control of Her-2 tumor immunity and thyroid autoimmunity by MHC and regulatory T cells. Cancer Res 67:7020-7027. https://doi.org/10.1158/0008-5472.CAN-06-4755

28. Piechocki MP, Pilon SA, Wei WZ (2002) Quantitative measurement of anti-ErbB-2 antibody by flow cytometry and ELISA. J Immunol Methods 259:33-42

29. Radkevich-Brown O, Piechocki MP, Back JB, Weise AM, PilonThomas S, Wei WZ (2010) Intratumoral DNA electroporation induces anti-tumor immunity and tumor regression. Cancer Immunol Immunother 59:409-417. https://doi.org/10.1007/s0026 2-009-0760-1

30. Gibson HM, Veenstra JJ, Jones R et al (2015) Induction of HER2 immunity in outbred domestic cats by DNA electrovaccination. Cancer Immunol Res 3:777-786. https://doi.org/10.1158/23266066.CIR-14-0175

31. Radkevich-Brown O, Jacob J, Kershaw M, Wei WZ (2009) Genetic regulation of the response to Her-2 DNA vaccination in human Her-2 transgenic mice. Cancer Res 69:212-218. https:// doi.org/10.1158/0008-5472.CAN-08-3092

32. Fattori E, Aurisicchio L, Zampaglione I et al (2009) ErbB2 genetic cancer vaccine in nonhuman primates: relevance of single nucleotide polymorphisms. Hum Gene Ther 20:253-265. https://doi. org/10.1089/hum.2008.153

33. Taneja V, David CS (1999) HLA class II transgenic mice as models of human diseases. Immunol Rev 169:67-79

34. Bergman PJ, Camps-Palau MA, McKnight JA et al (2006) Development of a xenogeneic DNA vaccine program for canine malignant melanoma at the Animal Medical Center. Vaccine 24:45824585. https://doi.org/10.1016/j.vaccine.2005.08.027
35. Bergman PJ, McKnight J, Novosad A et al (2003) Long-term survival of dogs with advanced malignant melanoma after DNA vaccination with xenogeneic human tyrosinase: a phase I trial. Clin Cancer Res 9:1284-1290

36. Liao JC, Gregor P, Wolchok JD, Orlandi F, Craft D, Leung C, Houghton AN, Bergman PJ (2006) Vaccination with human tyrosinase DNA induces antibody responses in dogs with advanced melanoma. Cancer Immun 6:8

37. Ferreira IG, Pucci M, Venturi G, Malagolini N, Chiricolo M, Dall'Olio F (2018) Glycosylation as a main regulator of growth and death factor receptors signaling. Int J Mol Sci 19:580. https ://doi.org/10.3390/ijms19020580

38. Lohmueller JJ, Sato S, Popova L et al (2016) Antibodies elicited by the first non-viral prophylactic cancer vaccine show tumorspecificity and immunotherapeutic potential. Sci Rep 6:31740. https://doi.org/10.1038/srep31740

39. Heeney JL, Dalgleish AG, Weiss RA (2006) Origins of HIV and the evolution of resistance to AIDS. Science 313:462-466. https ://doi.org/10.1126/science.1123016

40. Malhotra U, Nolin J, Mullins JI, McElrath MJ (2007) Comprehensive epitope analysis of cross-clade Gag-specific T-cell responses in individuals with early HIV-1 infection in the US epidemic. Vaccine 25:381-390. https://doi.org/10.1016/j.vaccine.2006.07.045

41. Misra M, Schein CH (2007) Flavitrack: an annotated database of flavivirus sequences. Bioinformatics 23:2645-2647. https://doi. org/10.1093/bioinformatics/btm383

42. Roque-Afonso AM, Ferey MP, Ly TD, Graube A, Costa-Faria L, Samuel D, Dussaix E (2007) Viral and clinical factors associated with surface gene variants among hepatitis B virus carriers. Antivir Ther 12:1255-1263

43. Piechocki MP, Ho YS, Pilon S, Wei WZ (2003) Human ErbB-2 (Her-2) transgenic mice: a model system for testing Her-2 based vaccines. J Immunol 171:5787-5794

44. Yong CS, Sharkey J, Duscio B et al (2015) Embryonic lethality in homozygous human Her-2 transgenic mice due to disruption of the Pds5b gene. PLoS One 10:e0136817. https://doi.org/10.1371/ journal.pone. 0136817

45. Wei WZ, Jacob JB, Zielinski JF, Flynn JC, Shim KD, Alsharabi G, Giraldo AA, Kong YC (2005) Concurrent induction of antitumor immunity and autoimmune thyroiditis in $\mathrm{CD}^{+}{ }^{+} \mathrm{CD} 25^{+}$regulatory T cell-depleted mice. Cancer Res 65:8471-8478. https://doi. org/10.1158/0008-5472.CAN-05-0934

46. Piechocki MP, Pilon SA, Wei WZ (2001) Complementary antitumor immunity induced by plasmid DNA encoding secreted and cytoplasmic human ErbB-2. J Immunol 167:3367-3374

47. Medina D, DeOme KB (1970) Effects of various oncogenic agents on tumor-producing capabilities of series D BALB-c mammary nodule outgrowth lines. J Natl Cancer Inst 45:353-363

48. Wei WZ, Malone K, Mahoney K, Heppner G (1986) Characterization of lymphocytic infiltrates in normal, preneoplastic, and neoplastic mouse mammary tissues. Cancer Res 46:2680-2685

Publisher's Note Springer Nature remains neutral with regard to jurisdictional claims in published maps and institutional affiliations. 